\title{
AVALIAÇÃO COMPARATIVA DE MÉTODO DE EXTRAÇÃO DE BANCADAS ALTAS E ULTRA-ALTAS, NO ESTADO DO ESPÍRITO SANTO
}

\author{
Rafael Franco e Silva ' \\ Rodrigo Carneiro Novaes ${ }^{2}$ \\ Heitor Passamani Fazôlo ${ }^{2}$ \\ Jodan Silva Volpasso ${ }^{2}$ \\ Gleicon Roberto de Sousa Maior ${ }^{2}$
}

\section{Resumo}

O Estado do Espírito Santo, sendo o maior exportador de rocha ornamental do país devido ao grande número de frente de extração que se encontra no estado, e para manter se competitivo neste mercado o setor está sempre em busca de novas tecnologias que venham a aumentar sua produção e reduzir seus custos. Com essa evolução o setor de rocha ornamental do espirito santo desenvolveu uma nova técnica de extração que são as bancadas ultra-altas, onde se deixar de utilizar as bancadas tradicionais de até $20 \mathrm{~m}$ e se passou a utilizar bancada que chegam a uma altura de $100 \mathrm{~m}$. Esta nova técnica possibilita maiores produções e uma melhor recuperação do material pétreo, além de aumentar a rentabilidade por ciclo de extração. Para que se possa utilizar este método, temos que observar alguns fatores como tipo de rocha, estado do maciço, investimentos iniciais mais altos, tempo para o desmonte e equipamentos específicos para o trabalho extração. Este tipo de método ainda não está bem difundido, pois no momento só é utilizado por algumas empresas nacionais, mas a sua eficiência é comprovada, se comparado com o uso das bancadas convencionais, este método pode gerar um lucro superior aos métodos convencionais.

Palavras-chave: Bancadas ultra-altas; Extração de granito; Produtividade; Boca de lobo.

\section{COMPARATIVE EVALUATION OF EXTRACTION METHOD FOR HIGH AND ULTRA-HIGH BENCHES, IN THE STATE OF ESPÍRITO SANTO.}

\begin{abstract}
The State of Espirito Santo, being the largest exporter of ornamental rock in the country due to the large number of extraction front that is in the state, and to remain competitive in this market, the sector is always in search of new technologies that will increase its production and reduce their costs. With this evolution the ornamental rock sector of the holy spirit has developed a new technique of extraction that are the ultra-high benches, where to stop using the traditional benches up to $20 \mathrm{~m}$ and started using benches that reach a height of $100 \mathrm{~m}$. This new technique allows for greater productions and a better recovery of the stone material, besides increasing the profitability per cycle of extraction. In order to use this method, we have to observe some factors such as rock type, solid state, higher initial investments, time for dismantling and specific equipment for the extraction work. This type of method is still not widespread, as it is currently only used by some national companies, but its efficiency is proven, compared to the use of conventional benches, this method can generate a profit higher than conventional methods.
\end{abstract}

Keywords: Ultra high benches; Granite extraction; Productivity; Wolf mouth.

\section{INTRODUÇÃO}

A extração de rocha ornamental pode ocorrer de diversos modos, a céu aberto em bancadas baixas (menores que $6 \mathrm{~m}$ ), em bancadas altas (alturas entre 6 à $20 \mathrm{~m}$ ), em bancadas ultra-altas (com alturas que podem chegar aos $100 \mathrm{~m})$ e, em alguns casos, através da lavra subterrânea. O Espírito Santo que é o principal Estado produtor de rocha

'Programa de Pós-graduação em Engenharia Mineral - PPGEMinas, Universidade Federal de Pernambuco - UFPE, Recife, PE, Brasil.

E-mail: rafaelfrancosil@gmail.com

${ }^{2}$ Instituto Federal do Espírito Santo - IFES, Cachoeiro de Itapemirim, ES, Brasil.

2176-1523 (c) 2019 Associação Brasileira de Metalurgia, Materiais e Mineração. Published by ABM. This is an open access paper, published under the Creative Commons CC BY-NC-ND license (Attribution-NonCommercial-NoDerivs) - https://creativecommons.org/licenses/ by-nc-nd/4.0/. 
ornamental no Brasil sendo o mesmo responsável por $70 \%$ das exportações brasileiras, desde o início da década de 70 até recentemente, as empresas têm optado em extrair blocos com bancadas de até no máximo 20 metros de altura [I].

Com o passar dos anos a tecnologias de lavra vem evoluído para melhor atender as necessidades das empresas do setor, este desenvolvimento possibilitou a elevação das alturas das bancadas, e com está elevação se desenvolveu uma nova técnica de extração conhecida como bancadas ultra-altas, que aumenta a produtividade das empresas e reduzem seus custos, viabilizando projetos que antes não se tornariam realidade.

São consideradas bancadas ultra-altas as bancadas que apresentam altura acima de $20 \mathrm{~m}$ podendo alcançar nos dias atuais até $100 \mathrm{~m}$, mas com a velocidade da evolução tecnológica, estas alturas logo vão ser superiores à $100 \mathrm{~m}$. Esta metodologia é aplicada em maciços de rocha competente e com elevadas cotas topográficas, onde não haveria possibilidade de se utilizar os métodos convencionais, já que a opção por este método se da nos relevos mais íngremes, onde se optarmos pelos métodos convencionais isso tornaria o processo mais oneroso. Está técnica já se encontra em uso no noroeste do estado do Espírito Santo, está nova técnica vem demonstrando ótimos resultados na recuperação de rocha ornamental e seu uso vem crescendo a cada ano [2].

A fase da pesquisa deve ser realizada com muito critério no que diz respeito às normas $A B N T$ NBR I 5.844/20 I 0 [3], pois vão ser coletadas as amostras onde será possível caracterizar o maciço rochoso, só após está caracterização onde será avaliada a competência do mesmo, é que haverá a possibilidade de decidir pela utilização das bancadas ultra-altas [4].

\section{METODOLOGIA}

Durante o período da pesquisa foi realizado um levantamento bibliográfico a respeito dos métodos de extração, evolução tecnológica, geologia e economia da região estudada. Por meio de levantamento de campo se verificou a aplicação destes métodos sendo possível verificar dados como volume extraído, recuperação do material pétreo, tempo de ciclo, consumo de fio diamantado e custo para extração do material.

De posse destes dados foi possível gerar uma planilha comparativa entre os dois métodos de interesse que são os de bancadas altas e ultra-altas, para verificar, qual o método que gera um melhor retorno ao longo de seu ciclo de extração.

\section{RESULTADOS E DISCUSSÕES}

Os afloramentos rochosos do noroeste do Espirito Santo são peculiares, pois são constituídos por terrenos proterozóicos, onde são comuns os picos isolados, denominados pontões e os pães de açúcar, possuindo certas dificuldades quanto à extração convencional de bancadas inferiores à $20 \mathrm{~m}$, pois além de sua dureza elevada, devido a composição mineralógica, o formato do seu afloramento não é favorável a implementação das bancadas convencionais. Devido a isso foram utilizadas bancadas de maior altura, com 30; 50 ou até mesmo de 100m como pode ser observado na Figura I [ 1$]$.

Com a evolução dos métodos de lavra e a dificuldade proporcionada pelo tipo de maciço, passou-se a desenvolver os métodos de bancadas ultra-altas para possibilitar a extração neste tipo de maciço rochoso. Mas para que isso possa acontecer, temos de garantir que o maciço rochoso seja competente, para isso deve-se realizar uma pesquisa detalhada, onde partir de amostras e furos de sondagens é possível analisar em laboratório se o maciço é competente e se o mesmo pode ser trabalhado em bancadas ultra-altas.

Para utilizar está técnica deve-se ter atenção ao maciço rochoso, quanto às falhas, fraturas e descontinuidades que por ventura possam vir a comprometer a estabilidade da bancada ultra-altas, pois são estas características que determinarão - máximo de altura que a bancada poderá alcançar, sem comprometer a estabilidade do maciço remanescente e a segurança das operações [5].
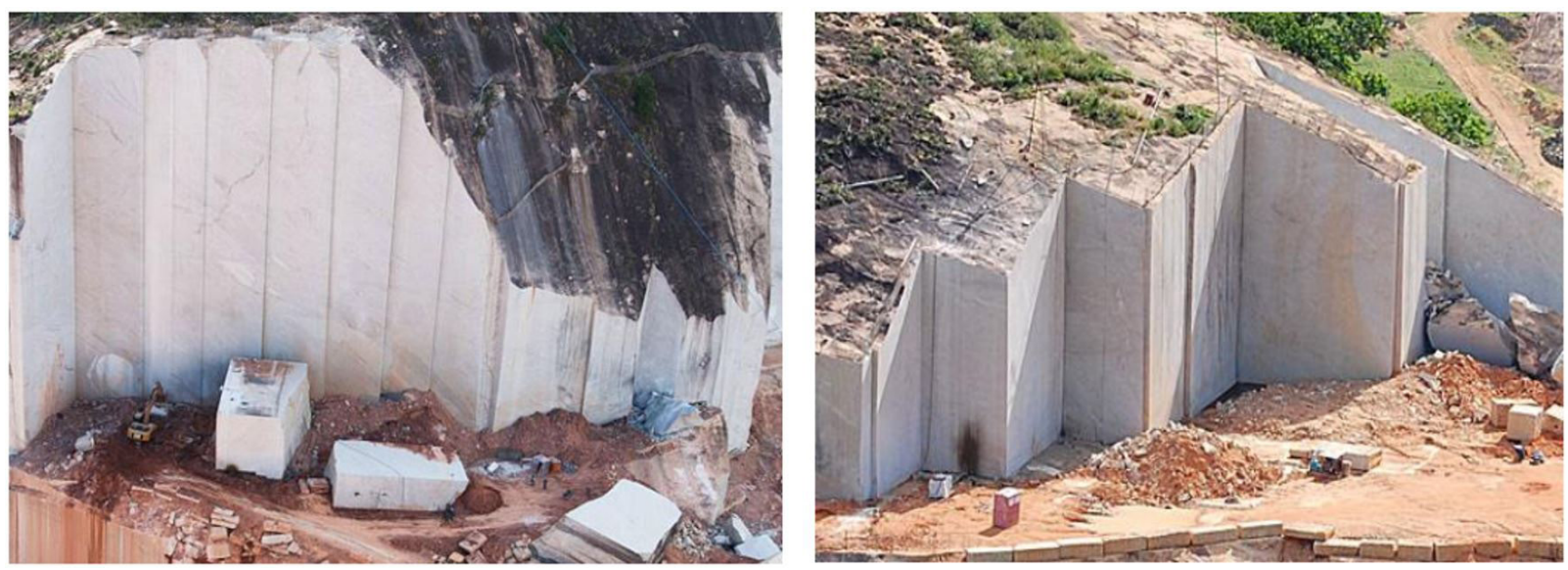

Figura I. Bancadas Ultra Altas no município de Barra de São Francisco no Noroeste do Espírito Santo [5]. 


\section{I Processo de Extração das Bancadas Ultra-Altas}

O processo de extração se dá através da perfuração com sondas rotativas até alcançar a altura desejada. Em seguida se fazem furos horizontais no pé da bancada de modo a encontrar com o primeiro furo executado na vertical. Após os dois furos se encontrarem passa-se um cabo guia que normalmente é o fio de náilon com auxilio do ar comprimido, só então o fio diamantado é inserido nos furos interligados. Posteriormente as duas extremidades do fio diamantado são unidas e só então se começa a executar o corte da bancada.

Para garantir que o fio diamantado passe por todo o furo deve-se, verificar quando sua profundida for superior aos $10 \mathrm{~m}$, pois estes furos podem sofrer desvios significativos, dificultando assim a etapa posterior. Os furos com alturas de $20 \mathrm{~m}$ a $100 \mathrm{~m}$ podem não se encontrar devido ao desvio causado no procedimento de perfuração sendo necessário realizar-se uma nova perfuração vertical para que estes furos se encontrem.

A interconexão dos furos horizontais e verticais é primordial para garantir a passagem do fio diamantado como vemos na Figura 2. Quando essa interconexão não ocorre devido aos desvios de furos ocorridos durante a etapa de perfuração da rocha, é necessário solucionar problema com pequenas detonações empregando cordel detonante nas extremidades internas dos furos.

\subsection{Utilizando o Fio Diamantado Após a Perfuração}

Já com os furos interconectados são passados os cabos-guias que na maioria das vezes são fios de náilon, este cabo guia passa por todo comprimento dos furos ao qual se pretende realizar o corte com fio diamantado com auxilio do ar-comprimido. $O$ fio diamantado é amarrado à ponta do cabo e assim o mesmo é puxado para a saída do furo. Para garantir um desgaste homogêneo das perolas do fio diamantado deve-se realizar uma torção que pode variar de I,5 a 2,0 voltas por metro de fio. Com o fio torcido é realizada a emenda através do engaste das duas extremidades do fio em tubos com rosca [6].

No início da operação de ser aplicada uma baixa velocidade periférica, que será aumentada gradativamente à medida que se obtenha $\mathrm{o}$ arredondamento das quinas de corte, adequando-se a velocidade de corte linear do fio ao tipo de material cortado, para que o fio não superaqueça durante este procedimento devido ao atrigo e tenha um desgaste pré-maturo se faz necessária a utilização de um fluxo de água continuo este fluxo de água também promove a remoção dos fragmentos gerados pelo corte, evitando assim, problemas no fio diamantado e no material que está sendo cortado (Figura 3) [7].

\subsection{Desmonte, Amortecimento e Corte Secundário Utilizando Fio Diamantado e Explosivo}

Já com a bancada isolada do maciço rochoso será necessário utilizar uma técnica conhecida como "Boca de Lobo" para promover o tombamento da bancada ultra-alta que se encontra isolada. Para se confeccionar a "Boca de
Lobo" que tem seu formato em cunha se faz necessário a realização de 2 furos, sendo um frontal inclinado na bancada e um lateral horizontal de formar que estes dois furos se interconectem, a etapa seguinte é a passagem do fio diamantado para promoter o corte da cunha como podemos observar na Figura 4.

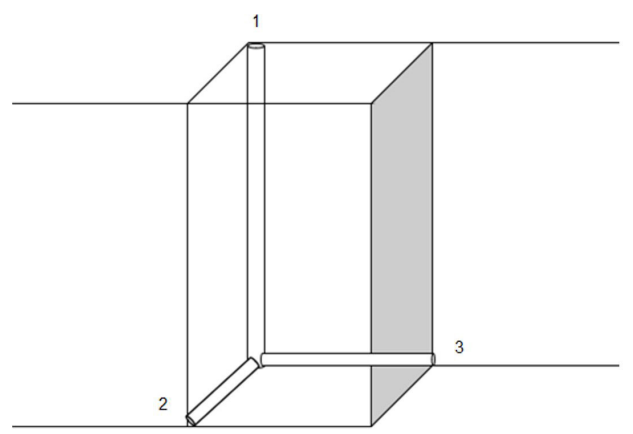

Figura 2. Representação de uma bancada ultra-alta, onde é possível verificar o furo I na vertical e os furos 2 e 3 na horizontal todos interconectados [6].

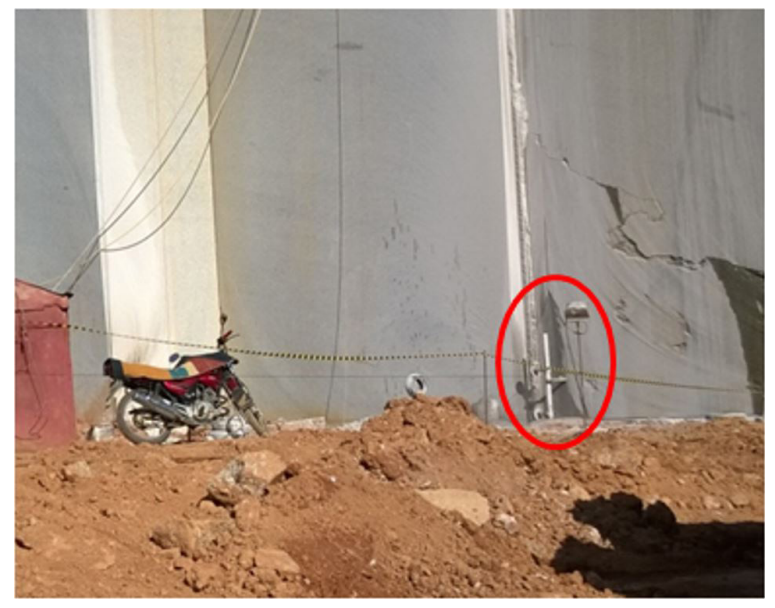

Figura 3. Em vermelho é possível observar o fluxo de água, durante a execução do corte com fio diamantado.

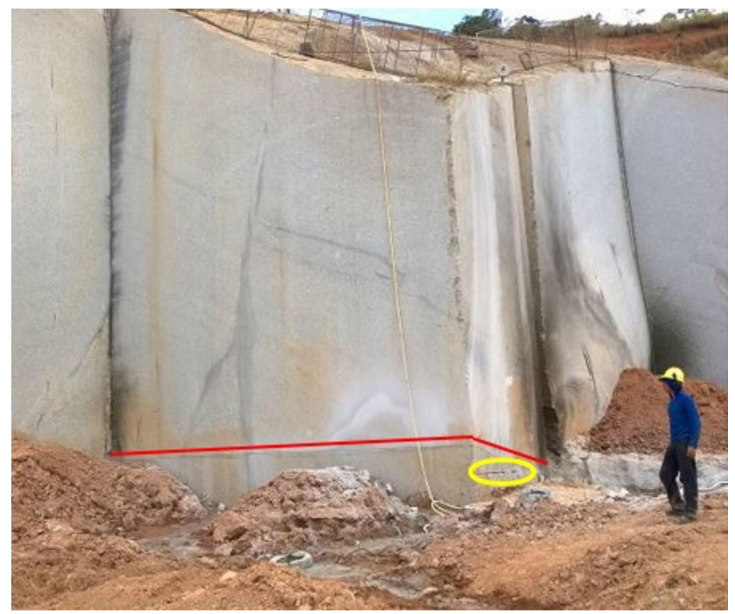

Figura 4. Em vermelho a "boca de lobo" já cortada com fio diamantado, com furos horizontais em amarelo onde será inserido explosivo, para realizar o desmonte da cunha e promover o tombamento da bancada ultra-alta [6]. 
Tabela I. Tabela comparativa entre métodos de lavra com bancadas convencionais e com bancadas ultra-altas, onde podemos ver o comprimento $(\mathrm{C})$, a largura $(\mathrm{L})$ e a altura $(\mathrm{H})$

\begin{tabular}{|c|c|c|c|c|c|c|}
\hline \multirow{3}{*}{ Dimensões (metros) } & \multicolumn{3}{|c|}{ Bancadas Altas } & \multicolumn{3}{|c|}{ Bancadas Ultra-Altas } \\
\hline & C & $\mathbf{L}$ & $\mathbf{H}$ & C & $\mathbf{L}$ & $\mathbf{H}$ \\
\hline & $15 x$ & $3 x$ & 20 & $20 x$ & $20 x$ & 100 \\
\hline Tempo total do ciclo (dias) & & 10 & & & 25 & \\
\hline Volume da bancada $\left(\mathrm{m}^{3}\right)$ & & 900 & & & 40.000 & \\
\hline Aproveitamento (recuperação) & & $15 \%$ & & & $25 \%$ & \\
\hline Volume final $\left(\mathrm{m}^{3}\right)$ & & 135 & & & 10.000 & \\
\hline Quantidade de fio necessário (metros) & & 75 & & & 230 & \\
\hline Custo médio de produção $\left(\mathrm{R} \$ / \mathrm{m}^{3}\right)$ & & 85,00 & & & 125,00 & \\
\hline Custo total por ciclo $(\mathrm{R} \$)$ & & $76.500,00$ & & & $5.000 .000,00$ & \\
\hline Preço de venda $\left(\mathrm{R} \$ / \mathrm{m}^{3}\right)$ & & 650,00 & & & 650,00 & \\
\hline Receita média de venda dos blocos ( $\mathrm{R} \$$ /ciclo) & & $87.750,00$ & & & $6.500 .000,00$ & \\
\hline Lucro por ciclo (R\$/ciclo) & & II $.250,00$ & & & $1.500 .000,00$ & \\
\hline Rentabilidade (\%) & & $12,82 \%$ & & & $23,08 \%$ & \\
\hline
\end{tabular}

Depois de confeccionada a "Boca de Lobo", são realizados furos horizontais na lateral da bancada ultra-alta como foi observado na Figura 4, estes furos vão ser preenchidos com explosivos, que após detonação quebram a cunha desestabilizando a bancada ultra-alta. Após o explosivo promover a quebra da cunha, a altura da "Boca de Lobo" deve ser suficiente para vencer a inercia da bancada ultra-alta realizando seu tombamento em uma cama de amortecimento, pois caso a inercia não seja vencida o tombamento da bancada será prejudicando se tornando obrigatório a utilização de técnicas adicionais, como por exemplo, a utilização de cabos de aço preso na bancada e em uma pá carregadeira para puxar a bancada e promover seu tombamento, que vai ser amortecido por uma cama de argila que se encontra logo à frente da bancada.

Está cama é montada com material do decapeamento do avanço da frente de extração, ou de outros trabalhos mineiros. Em muitos casos este material não é suficiente sendo necessária a utilização de uma área de empréstimo já que os volumes da cama tem que ser compatível com o volume da bancada que está sendo derrubada, evitando danos e quebras na fase de tombamento.

A metodologia de bancadas ultra-altas foi desenvolvida pelo segmento de rocha ornamental com o objetivo de aumentar sua produtividade, por ser um método utilizado para reduzir os números de ciclos, possibilitando trabalhar com uma grande quantidade de material, sem necessitar a confecção de camas de amortecimento mais complexas, levando a um ganho de produtividade.

De posse dos dados, podemos falar que no cenário atual, utilizam-se bancadas ultra-altas apenas em rochas ornamentais com resistência superior a I $25 \mathrm{Mpa}$, desta forma garantindo que as bancadas ultra-altas tenham resistência suficiente para suportar os esforços necessários do processo de extração [I].

Com o ganho de produção devido à utilização de bancadas ultra-altas, o mercado consumidor deve demandar um consumo compatível com esse alto nível de produção. Podemos comprovar os ganhos reais advindos da metodologia de extração através de bancadas ultra-altas, com as informações adquiridas junto às empresas do setor de rocha ornamental, como observado na Tabela I, é possível verificar de forma comparativa os custos de produção e as receitas do método convencional, com o desmonte das bancadas ultra-altas.

De posse dos dados da Tabela I é possível verificar que as bancadas ultra- altas requerem maior tempo de ciclo, devido ao volume maior também vai ter um consumo maior de fio diamantado, assim como os equipamentos vão passar trabalhando mais tempo neste ciclo, o que gera um custo final mais elevado se comparado ao método tradicional. Embora haja estes elevados custos e consumos, a resposta financeira é muito superior por ciclo de extração.

As empresas do setor que utilizam este método de extração são as empresas de grande porte, pois as mesmas possuem um melhor aporte financeiro para aquisição de equipamentos de grande porte que permitam $\circ$ trabalho com está metodologia de extração.

Pensando sempre em reduzir custos, aumentar à produtividade das empresas do setor de rocha ornamental buscam inovações no mercado seja de equipamentos ou de métodos de trabalho que ajudem no processo de redução de custo. A utilização do método de bancadas ultra-altas, apesar de aumentar o custo produtivo, o mesmo também aumenta a recuperação do material pétreo, o que torna este método de extração mais eficaz que o método convencional. A utilização deste método tem sua eficácia comprovado devido à rentabilidade que é superior ao dos métodos convencionais, com a rentabilidade superior espera-se um retorno rápido dos investimentos realizado pelo empreendedor.

\section{CONCLUSÃO}

Diante do exposto podemos concluir que o método das bancadas ultra-altas é mais eficiente que os métodos convencionais, já há um ganho de produção e um aumenta da recuperação de material extraído, que influencia diretamente em questões ambientais como a redução do bota fora de 
rejeitos, apesar deste método ter um custo mais elevado que os métodos tradicionais, esse custo são considerados insignificantes devido ao aumento da recuperação e da produção.

Além do ganho produtivo temos um aumento significativo da rentabilidade do empreendimento, com este ganho na rentabilidade podemos viabilizar empreendimento antes considerado inviável, também podemos esperar um melhor payback, mas só é possível confirmar isso quando realizarmos um fluxo de caixa completo dos empreendimentos.

A empregabilidade deste método tem seus desafios, pois necessita de diversas informações sobre as características tecnológicas do maciço rochoso, como a resistência mecânica e deformação, que está informação é de suma importância para se verificar a qualidade do maciço rochoso no que se diz respeito a suportar as alturas elevadas do método de bancadas ultra-altas, mas também se fazem necessários os demais testes para verificar a homogeneidade do maciço além de verificar se ele é isotrópico, linear e estável.

Devido à melhora na rentabilidade do empreendimento e da recuperação dos maciços rochosos, este método deve ser mais bem divulgado para que não se torne conhecido apenas no Espirito Santo, ou por uma pequena quantidade de empresas do setor, deve-se buscar difundir está técnica no Brasil e em outros países, pois existem locais onde eles possam ser aplicados, mas por falta de conhecimento não está sendo aplicado podendo até está inviabilizando projetos de extração de rocha ornamental.

\section{REFERÊNCIAS}

I Sardou R. Fo, Matos GMM, Mendes VA, Iza ERHF. Atlas de rocha ornamental do Espirito Santo. Brasília: CPRM; 2013.

2 Vidal FWH, Pinheiro JR, Castro NF, Caranassios A. Tecnologia de rochas ornamentais, pesquisa, lavra e beneficiamento. Rio de Janeiro: Editora CETEM/MCTI; 20 I4.

3 Associação Brasileira de Normas Técnicas. ABNT NBR 15.844: Rochas para Revestimento - Requisitos para Granitos. Rio de Janeiro: ABNT; 2010.

4 Silva RF, Rodrigues AS, Barros MLSC, Oliveira FMC, Vasconcelos SLD. Caracterização tecnológica de rocha pegmatítica visando sua utilização como rocha ornamental. TMMM - Tecnologia Materiais Metalurgia e Mineração. 20I8; I5(4):434-440.

5 Maior GRS. Estabilidade dos maciços rochosos para lavra de granito com bancadas ultra-altas. Anais do IX Simpósio de Rochas Ornamentais Do Nordeste; 2016; João Pessoa, PB. Rio de Janeiro: CETEM - Livros Publicados; 2016.

6 Silva RF, Barros MLSC, Assis MS. Padronização da metodologia de ruptura basal em cunha, para tombamento de painéis verticais na lavra de rocha ornamental. TMMM - Tecnologia Materiais Metalurgia e Mineração. 2019;16(I):57-6I.

7 Fazolo HP, Maior GRS. Aplicação da metodologia de lavra de rocha ornamental por bancadas ultra altas nas minerações de granito no norte do Espírito Santo. In: IX Simpósio De Rochas Ornamentais Do Nordeste. João Pessoa - PB, 2016.

Recebido em: 15 Nov. 2018

Aceito em: 25 Maio 2019 